\title{
A CLASS OF ANALYTIC FUNCTIONS INVOLVING THE DZIOK-RAINA OPERATOR
}

\author{
NENG XU AND R. K. RAINA
}

\begin{abstract}
This paper first defines a class of analytic functions which is associated with the DziokRaina operator and related closely with the class of uniformly convex functions. Several characteristics for this class of functions are investigated which include certain inclusion relations, convolution properties and the order of starlikeness. Several cases and implications of the main results including the concept of subordinations are discussed and some consequent results are also pointed out.
\end{abstract}

Mathematics subject classification (2010): 30C45.

Keywords and phrases: Uniformly convex functions, convex univalent functions, starlike functions, $\alpha$-spirallike functions, Wright generalized hypergeometric function, Dziok-Raina operator, subordination.

\section{REFERENCES}

[1] S. D. Bernard, Convex and starlike univalent functions, Trans. Amer. Math. Soc. 135 (1969), 429 446.

[2] B. C. CARLSON AND D. B. SHAFFER, Starlike and prestarlike hypergeometric functions, SIAM J. Math. Anal. 15 (1984), 737-745.

[3] J. DZIOK AND R. K. RAINA, Some results based on first order differential subordination with the Wrights generalized hypergeometric function, Comment. Math. Univ. St. Pauli 58(2009), 87-94.

[4] J. DzIOK AND R. K. RAINA, Families of analytic functions associated with theWright generalized hypergeometric function, Demonstratio Math. 37 (2004), 533-542.

[5] J. Dziok AND H. M. SRIVAstaVA, Classes of analytic functions associated with the generalized hypergeometric function, Appl. Math. Comput. 103 (1999), 1-13.

[6] A. Gangadharan, T. N. Shanmugam and H. M. Srivastava, Generalized hypergeometric function associated with k-uniformly convex functions, Comput. Math. Appl. 44 (2002), 1515-1526.

[7] A. W. Goodman, On uniformly convex functions, Ann. Polon. Math. 56 (1991), 87-92.

[8] A. W. Goodman, On uniformly starlike functions, J. Math. Anal. Appl. 155 (1991), 364-370.

[9] S. KANAS AND H. M. SRIVASTAVA, Linear operators associated with $k$-uniformly convex functions, Integral Transform. Spec. Funct. 9 (2000), 121-132.

[10] S. S. Miller and P. T. Mocanu, Differential Subordinations: Theory and Application, vol. 225 of Monographs and Textbooks in Pure and Applied Mathematics, Marcel Dekker, New York, NY, USA, (2000).

[11] S. OWA, On uniformly convex functions, Math. Japon. 48 (1998), 377-384.

[12] R. K. RAINA, Certain subclasses of analytic functions with fixed argument of coefficients involving the Wright's function, Tamsui Oxford J. Maths. 22 (2006), 51-59.

[13] R. K. RAINA AND P. SHARMA, Harmonic univalent functions associated with Wright's generalized hypergeometric functions, Integral Transform. Spec. Funct. 22, 8 (2011), 561-572.

[14] R. K. RAina AND G. MURUgusundaramoORTHY, On a subclass of harmonic functions associated with Wright's generalized hypergeometric function, Hacettepe J. Math. Stat. 38, 2 (2009), 129-136. 
[15] R. K. Raina, G. Murugudundarmoorthy and N. Magesh, Subordination and superordination properties for analytic functions involving Wright's functions, Le Matematiche 66, 1 (2011), $65-67$.

[16] F. RøNNING, Uniformly convex functions and a corresponding class of starlike functions, Proc. Amer. Math. Soc. 118 (1993), 189-196.

[17] S. Ruscheweyh, New criteria for univalent functions, Proc. Amer. Math. Soc. 49 (1975), 109-115.

[18] N. SARkar, P. Goswami, J. Dziok AND J. Sokó L, Subordination for multivalent analytic functions associated with Wright generalized hypergeometric function, Tamkang J. Math. 44, 1 (2013), $61-71$.

[19] J. SoкóŁ, On some applications of the Dziok-Srivastava operator, Appl. Math. Comp. 201 (2008), 774-780.

[20] J. SoKóŁ AND K. PiejKo, On the Dziok-Srivastava operator under multivalent analytic functions, Appl. Math. Comp. 177 (2006), 839-843.

[21] H. M. Srivastava, Ding-Gong Yang and Neng Xu, Subordinations for Multivalent Analytic Functions Associated with the Dziok-Srivastava Operator, Integral Transform Spec. Funct. 20 (2009), 581-606.

[22] T. J. SuffRIDGe, Some remarks on convex maps of the unit disk, Duke Math. J. 37 (1970), 775-777.

[23] E. M. WRIGHT, The asymptotic expansion of the generalized hypergeometric function, Proc. London Math. Soc. 46 (1946), 389-408.

[24] N. XU, D.-G. YANG AND J. SokóL, A Class of Analytic Functions Involving the Dziok-Srivastava Operator, J. Inequal. Appl. 138 (2013), 1-15. 